\title{
Making Transitions Possible: Students with Disabilities and Paths Beyond High School
}

\author{
Natalie Xiomara Aguilar \\ Loyola Marymount University
}

\begin{abstract}
Students with learning disabilities in the United States lag behind in college enrollment and higher education attainment when compared to their neurotypical counterparts. Secondary education is mandated under US legislation, IDEA to provide transition plans beginning at age 14 all the way through high school graduation, however, college enrollment and college preparation is an afterthought for students that present with learning challenges. Self-advocacy and skills such as self-determination should be part of a student's natural learning trajectory within the k-12 setting; especially as part of their participation in IEP (Individualized Education Plan) meetings. However, current models of special education and IEP delivery are failing students within the transition process. Service providers and educators are working in silos, however, are expected to seamlessly provide students with a framework to successfully transition into emerging adulthood. Issues concerning students with disabilities go beyond addressing individual needs. While legal compliance should always be a goal for schools, educators should consider frameworks of support that encourage student participation and engagement. Formal processes such as IEP's and providing accommodations in school settings address skill development as well as equity; however, educating students should universally consider equipping students with skills necessary for the natural transition into emerging adulthood. This paper outlines the issues in US school systems as they relate to students with learning disabilities while outlining problems in policy and practice within education. Suggestions for psychoeducational and institutional interventions at the secondary and postsecondary level are outlined within the frameworks of self-determination, selfregulation, and equity.
\end{abstract}

Keywords: higher education; Individual Education Plan; learning disabilities; selfdetermination; self-regulation 